\section{Misconduct: forum should not be used to settle scores}

SIR - Although China is developing its science and technology at an unprecedented speed, scientific misconduct is a serious issue, as you have highlighted in your Special Report "Named and shamed" (Nature 441, 392-393; 2006).

Shi-Min Fang, the webmaster of New Threads (www.xys.org), has defended, in Correspondence (Nature 441, 932; 2006), this website's role in disclosing scientific misconduct on occasions when the authorities have ignored whistleblowers.

Like many other Chinese scientists working overseas, I care very much about scientific misconduct in China. However, I have also been concerned for a long time about the quality of articles published on New Threads. Often, I find that there are few facts and little investigation behind the accusations, and that many articles are mixed with assumptions and personal attacks on named scientific researchers.

One such example is that of Hualiang Jiang, a principal investigator working at the Shanghai Institute of Materia Medica. Because I work in a similar field, I am familiar with Jiang's work and publications, although I have never met him. New Threads contains several articles (urls provided) attacking Jiang personally, using many insulting words such as "idiot". It seems that some of the articles were written by someone who may have been an unsuccessful job candidate at Jiang's institute.

Disclosing scientific misconduct is not simply about free speech, as claimed by Fang. It is also about being professional, objective and serious. Only verified facts should be published on the website, if it is claiming to monitor incidents of scientific misconduct. It should not be used for unsubstantiated attacks in the name of free speech, not only because of the personal and professional effects on the scientists concerned, but also because readers, especially young students, could be misled. Guosheng Wu 700 Lower State Road, North Wales, Pennsylvania 19454, USA

\section{Misconduct: China needs university ethics courses}

SIR - Your Special Report "Named and shamed" (Nature 441, 392-393; 2006) and Editorial "Finding fraud in China" (Nature 441, 549-550; 2006) report that scientific misconduct has become rampant in China, especially in universities. I would like to add my view to those of previous correspondents (Nature 441, 932; 2006).
Misconduct is hampering the sound development of science in the nation's highereducation system. If scientific misconduct cases are not handled by the university (or other concerned authority), and muchneeded outside supervision is not available, then each occasion that comes to light damages the academic reputation of the university concerned, the whistleblower and the person accused.

Unfortunately, serious and justified investigations of suspected fraud have been largely ignored by China's universities, with the exceptions of the prestigious Tsinghua University and Shanghai Jiaotong University, each of which has recently dismissed a professor (returned from abroad in each case) for fabricating research achievements or results. However, details of these investigations have not been disclosed, so other universities cannot learn from them.

Obviously, it is the university involved in a fraud case - not the Ministry of Education, the media, websites, journals or newspapers - that has the power to dismiss or demote the accused, if guilty. A mechanism is needed to deal with such eventualities.

To cope with embarrassing situations such as those currently being highlighted in the media, I suggest that editorials and articles on the subject in science journals such as Nature and Science should be used as materials for teaching a course of research ethics to students in China's universities. Access to case studies being taught in scientific ethics courses elsewhere would also be valuable. Our universities should play a key part in fighting scientific misconduct, and every honest Chinese professor should make a contribution to such courses as part of providing a complete university education. Qizhi Wang

Department of Mechanics, College of

Architecture and Environment, Sichuan University, Chengdu, Sichuan 610065, China

\section{Rushed decision on collider would limit useful options}

SIR - Your Editorial about the International Linear Collider (ILC), "Making collider endorsement count" (Nature 440, 1089; 2006), states that CERN has insisted "that decisions about the siting of the ILC be delayed until an accelerator technology it is trying to develop is ready". This is untrue.

CERN's position is that no irreversible decision on building a linear collider should be taken until the end of the decade. By that time, the Large Hadron Collider - the particle-physics community's current flagship facility - will have produced its first results, a full technical design for the ILC will be ready, and we will know whether the technology for a more powerful compact linear collider (CLIC) is feasible. These ingredients will allow the global particlephysics community to take an informed and responsible decision on its future. Moreover, funding is simply not available on a shorter timescale for such a huge project to begin.

You report that some in the community find CERN's position "self-serving". Yet this is by definition not possible, given that it implements the decisions taken by its 20 member states. The organization's position on the ILC is necessary to ensure the optimum use of public resources in this exciting area of research. Contrary to the implication in your Editorial, CERN has accelerated research and development on CLIC precisely so as not to delay the decision on the ILC.

Also contrary to the implication in your Editorial, CERN contributes to the ILC by providing personnel and material resources, and by participating in European networks for ILC research and development.

Robert Aymar

CERN, Geneva 23, CH-1211, Switzerland

\section{Speaking for Taiwan about colours, maps and politics}

SIR - In your News Feature "Forward planning” (Nature 440, 987-989; 2006), you published a map of East Asia in which Taiwan and China are both coloured yellow, indicating that they comprise one country. Yet Taiwan and China have been governed separately since 1949, when the Chinese communists ousted the nationalists from the mainland in a civil war.

Since then, Taiwan (officially called the Republic of China) has undergone a complete process of democratization, while China (officially called the People's Republic of China) has continued under single-party communist rule. This is a reality that cannot be ignored. If a reporter from Nature needed to visit Taiwan on assignment, for example, he or she could not apply for a visa at the Chinese embassy.

I hope that in future Nature will take into account the fact that Taiwan and China are governed separately as two distinct countries. Michael Chen

Taipei Representative Office in the United

Kingdom, 50 Grosvenor Gardens,

London SW1W OEB, UK

Nature's long-standing policy is to abide by the United Nations' position on the status of Taiwan - Editor, Nature.

\footnotetext{
Contributions to Correspondence may be submitted to corres@nature.com.They should be no longer than $\mathbf{5 0 0}$ words, and ideally shorter. They should be signed by no more than three authors; preferably by one. Published contributions are edited.
} 